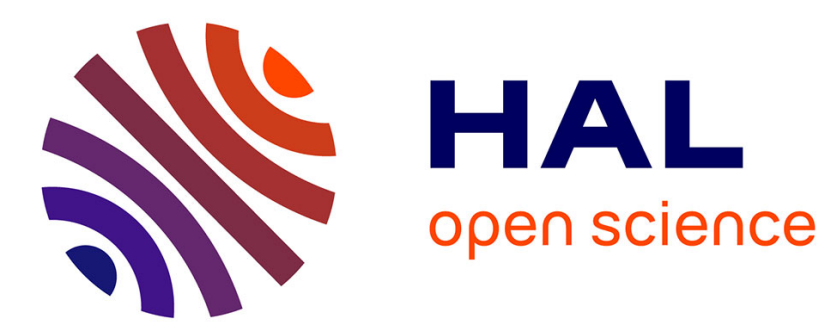

\title{
In What Sense Is Knowledge the Norm of Assertion? Pascal Engel
}

\section{To cite this version:}

Pascal Engel. In What Sense Is Knowledge the Norm of Assertion?. Grazer Philosophische Studien, 2008, 77 (1), pp.99-113. halshs-01200551

\section{HAL Id: halshs-01200551 https://shs.hal.science/halshs-01200551}

Submitted on 23 Sep 2015

HAL is a multi-disciplinary open access archive for the deposit and dissemination of scientific research documents, whether they are published or not. The documents may come from teaching and research institutions in France or abroad, or from public or private research centers.
L'archive ouverte pluridisciplinaire HAL, est destinée au dépôt et à la diffusion de documents scientifiques de niveau recherche, publiés ou non, émanant des établissements d'enseignement et de recherche français ou étrangers, des laboratoires publics ou privés. 


\title{
IN WHAT SENSE IS KNOWLEDGE THE NORM OF ASSERTION?
}

\author{
Pascal Engel \\ Université de Geneve
}

\begin{abstract}
Summary.
The knowledge account of assertion (KAA) is the view that assertion is governed by the norm that the speaker should know what $\mathrm{s} /$ he asserts. It is not the purpose of this article to examine all these criticisms nor to try to give a full defence of KAA, but only to defend it against the charge of being normatively incorrect It has been objected that assertion is governed by other norms than knowledge, or by no norm at all. It seems to me, however, that a number of these criticisms are based on a number of misunderstandings of the notion of a norm and of the way it can regulated a given practice. Once we spell out in what sense knowledge can play a normative role in this context, the KAA appears much more plausible.
\end{abstract}

\section{Preliminary formulations of the knowledge account}

The knowledge account of assertion (KAA), although it has probably been present within philosophy at least since the Pyrrhonian sceptics ${ }^{1}$, was introduced within contemporary analytic philosophy by G.E. Moore (1962), revived by Michael Slote (1972) and Peter Unger (1975) and Timothy Williamson (2000) $)^{2}$. It has since received as much approval as criticism. It consists in at least the following three claims:

There is a norm for the speech act of assertion

This norm is unique and constitutive of assertion

This norm is that one must assert that $\mathrm{P}$ only if one knows that $\mathrm{P}$

Each of these claims can be contested. One can reject the idea that there is a norm for the practice of assertion: maybe there are no rules or norms for this practice, and just things that people say in various circumstances, which can all equally count as assertions. One can also reject the idea that if there is a norm it is unique and constitutive. There might be

\footnotetext{
1 Although it has, to my knowledge, not been often remarked, the Pyrrhonian sceptic's refusal to assent fully to propositions is based on the implicit recognition that knowldedge is the norm of assertion. see Frede's (1984) classical article.

${ }^{2}$ The knowledge account surfaces also in some writings by Ruth Marcus, such as her (1983), where she holds that to believe that $\mathrm{P}$ implies that $\mathrm{P}$ is possible, and one's realisation that $\mathrm{P}$ is impossible leads to a withdrawall of one's claim to believe, and in appropriate conditions of one's having asserted that P. In other words, realisation that one does not know that $\mathrm{P}$, since $\mathrm{P}$ cannot but be false when $\mathrm{P}$ is impossible, amounts to the realisatin that one is not entitled to assert that $\mathrm{P}$.
} 
several kinds of norms, including ones which do not involve any epistemic position on the part of the asserter. And one can reject the knowledge norm itself, and propose a weaker one, while accepting that the norm of assertion is some epistemic status. The other obvious candidates are the weaker norms of truth and a norm of belief:

(KT) One must assert that $\mathrm{P}$ only if $\mathrm{P}$ is true

(KB) One must assert that $\mathrm{P}$ only if one believes that $\mathrm{P}$

or perhaps some higher condition than mere belief, alternatively :

(KRB) One must assert that $\mathrm{P}$ only if one rationally believes that $\mathrm{P}$

(KWB) One must assert that $\mathrm{P}$ only if $\mathrm{P}$ is warranted

(KPB) One must assert that $\mathrm{P}$ only if $\mathrm{P}$ is highly probable

In this article, I will not really discuss the issue of whether one should defend (KT) or one of the norms (KB), which all presuppose that the norm of assertion involve some epistemic status, low or high, on the part of the speaker. I shall be mainly concerned with the sense in which either of these can be said to a norm of assertion. For that, I shall also suppose that the norm for assertion is at least as strong as $(\mathrm{KN})$. Even if we assume that (i)-(iii) are correct, there are, nevertheless, several formulations of (iii), which are not equivalent. The most basic one says that an assertion that $\mathrm{P}$ is correct if and only the speaker knows that $\mathrm{P}$, hence obeys the prescription:

(KN) One must: assert that $\mathrm{P}$ only if one knows that $\mathrm{P}$

This is Williamson's (2000: 243) formulation. Moore's own version is distinct: "By asserting that $\mathrm{P}$, you imply, though you do not assert, that you know that $\mathrm{P}$ (Moore 1962: 277).

( MKN) To assert that $\mathrm{P}$ is to imply that one knows that $\mathrm{P}$

Peter Unger's formulation differs too: “Asserting that something is so entails not just representing the thing as being so, but representing oneself as knowing that it is." (Unger 1975: 256) 
(SPKN) To assert that $\mathrm{P}$ is to represent oneself as knowing that $\mathrm{P}$

Let us call this, with Pagin (2006), the "self-presentation account". The self- presentation account is clearly the counterpart of similar claims which have been proposed for the belief account of assertion (KB). Thus Dummett has suggested:

"A man makes an assertion if he says something in such a manner as deliberately to convey the impression of saying it with the overriding intention of saying something true" (Dummett 1973: 300)

and Davidson similarly:

"What is understood [by the hearer of an assertion by a speaker] is that the speaker, if he has asserted something, has represented himself as believing it - as uttering a sentence he believes true, then. But it is not a convention, it merely part of the analysis of what assertion is. To assert is, among other things, to represent oneself as believing what one asserts". (Davidson 1979)

The self-presentation analysis transposes this claim from belief to knowledge.

As one sees, these formulations are not equivalent and their differences can generate a lot of ambiguities. In the first place it is not clear whether they are supposed to give a defining feature of assertion, or at least to give a necessary condition of it, as $(\mathrm{KN})$ does, or whether they are giving the condition of a successful assertion. On the first reading, a statement which would not conform to the $(\mathrm{KN})$ norm would fail to be an assertion. On the second reading, it might be an assertion but a defective one. In the second place (KN) and the other two formulations (MKN) and (SPKN) differ in that the latter two do not require that the speaker actually knows that $\mathrm{P}$, but only that he conveys to his audience the belief that he does, whereas the former does require that the speaker actually knows that $\mathrm{P}$, and is compatible with the following:

(KNB) One must: assert that $\mathrm{P}$ only if one believes that one knows that $\mathrm{P}$

There is at least one version of the self-presentation account (SPKN) which is clearly defective, for reasons which have been clearly brought up by Peter Pagin (2006). Suppose that a speaker represents herself as knowing that $\mathrm{P}$ by simply saying 
I hereby represent myself as knowing that $\mathrm{P}$

But an utterance of (1) is obviously not an assertion that $\mathrm{P}$, for conveying to an audience, successfully or not, the belief that one knows that $\mathrm{P}$ cannot amount to asserting that $\mathrm{P}$. When one asserts that $\mathrm{P}$, what one says implies that $\mathrm{P}$, and is incompatible with its falsity. (1), however, is compatible with the falsity of P. This is not simply because one may lie: one may commit oneself, through some sort of act - for instance a statement before a tribunal, which legally ties one to the truth of $\mathrm{P}$, without it being the case that $\mathrm{p}$ is actually true. Asserting that $\mathrm{P}$ is more than committing oneself to some audience, through some sort of social commitment. In other words, it is something different from assuring someone that $\mathrm{P}$. It is saying that $\mathrm{P}$ with the aim of saying something true, and not simply saying something which one represents to others as true, and that one believes as true. An actor on the stage might, in this sense, represent himself as knowing that $\mathrm{P}$ without asserting that P. For the same reason, the self-presentation account does not work when the speaker is supposed to commit herself to the belief that $\mathrm{P}$ :

(2) I hereby represent myself as believing that $\mathrm{P}$

is just as inadequate as (1) for the same reasons. The same goes for

(3) I hereby represent myself as committed to the truth that P

which is no more an assertion that $\mathrm{P}$ than $(1) .^{3}$

This may have to do with the reason why Moore says that to assert that $\mathrm{P}$ is not to assert that one knows that $\mathrm{P}$, but only to imply it. But it remains to be seen in what sense there is such an implication in assertion. The inadequacy of the formulations (1), (2) and (3) does not rule out the self-presentation account in itself, since there may be more adequate formulations of it (I shall come back to that below). I shall however, assume first that the correct account is $(\mathrm{KN})$.

\footnotetext{
${ }^{3}$ Pagin 2006 . Pagin develops in his 2005 a general strategy for assessing claims about speech acts.
} 


\section{Familiar objections to $\boldsymbol{K A A}$}

Several kinds of arguments have been advanced in favour of $(\mathrm{KN})$. The most familiar ones appeal to linguistic evidence. Asserting that $\mathrm{P}$ invites the question "How to do you know?" when the assertion is improper, or "You don't know that", when it is false.

Similarly asking the question whether $\mathrm{P}$ seems to imply that one ignores whether $\mathrm{P}$. The point is that when a speaker asserts that $\mathrm{P}$, and does not know that $\mathrm{P}$, he can be criticised, or has to withdraw his assertion. Similarly if you ask whether P while you already know that $\mathrm{P}$, you have in some sense failed to ask a question, or have violated Grice's maxim of quality. This linguistic evidence is not very compelling, though. In a number of contexts, utterances that P can elicit questions like: "What are your reasons for believing P?" or "Do you believe that?" which suggest that reasonable grounds for belief, or simply truth, are the proper presuppositions of assertion. And some questions are just ironical. For instance the following dialogues make perfectly good sense:

(4) "LakeLeman is polluted." - What are your reasons to believe this?

(5) "Hillary Clinton will be the next president" - Do you believe this ?

(6) "Have you not received the Nobel prize yet?" - You are kidding!

An argument based on Moore's paradox has also been advanced in favour of KN. It consists in remarking that sentences like

(7) It is raining, but I do not know it

are just as absurd as the familiar Moorean sentences such as "It is raining but I don't believe it" or "I believe it is raining but it's not". Indeed sentences like (7) are much more clearly absurd than these. But one may remark that

(7') It is raining, but I do not have very good reasons for believing it.

does not make sense either. So why should the presence of "know" in (7) make the difference?

The lottery argument is perhaps the most discussed (Williamson 2000: 246-47). The point is that an assertion made only on the basis of a very high degree of belief can be straightforwardly rejected. In a fair lottery of 10000 tickets where A has bought one ticket, if B says: "Your ticket did not win", A is entitled to assert : "But you do not know 
that !" Here too there is a defence in terms of rational belief. Someone could as well answer: "But you do not have enough grounds to believe this!"

Another related argument appeals to the role of knowledge in practical reasoning. Hawthorne (2004) presents the following piece of reasoning coming from an individual participating in a fair lottery:

(1) My ticket will not win

(2) If I keep my ticket, I shall win nothing

(3) If I sell my ticket, I'll get 10 pence

(4) Hence I must sell my ticket

The reasoning is wrong, because the individual is not entitled to (1) in the first place, for his premise is not known. The point is that knowledge plays an indispensable role in practical reasoning. But here too it is not clear that rational belief could not be the appropriate norm: we seem entitled to affirm things of which we are not absolutely certain in the sense of knowledge (Douven 2006).

Other objections to $(\mathrm{KN})$ concentrate on the many circumstances where assertion seems to be proper even when one does not know that P (Weiner 2005). They include cases of lying (a liar does not even believe what he says, hence does not know it), ironical assertions, gossips where one merely "says" that P in the coffee house without asserting it seriously, cases of assertions about future events ("The next American president will be Barack Obama") which we feel perfectly entitled to assert even though we do not know that they are true, cases of agents who are in a Gettier situation, where they are justified to believe something true merely by accident ("Nogot owns a Ford”, " This is a barn façade"), or cases where the circumstances allow us to assert something for reasons which have nothing to do with any epistemic status. For instance, I may assert "That's your train!" in a circumstance where I am not sure that it is your train, although it is very important for you to take a train (if it were not your train, you would not be entitled to criticize me for not knowing) (Williamson 2000: 256). Or I may say to you, when you are worried by a very serious problem: “That's not a big deal”, when I actually know that it's a big deal.

Another similar kind of objection involves situations where assertions are proper in the presence of other norms than purely epistemic ones. Jennifer Lackey (2007) has presented cases of what she calls "selfless assertions", where a subject, for purely non epistemic reasons does not believe that $\mathrm{P}$, but is aware that $\mathrm{P}$ is well supported by 
epistemic reasons, hence is led to assert that $\mathrm{P}$, although he still does not believe that $\mathrm{P}$, hence does not know that $\mathrm{P}$. She gives the case of a racist juror who because of his prejudices is led to believe that a black man is guilty although he recognises the racist origin of his prejudice and asserts that the man is innocent, or the case of a creationist teacher who nevertheless is able to recognise the scientific evidence against her religious beliefs and is led to assert evolutionist claims. According to Lackey, in those cases, the agent, qua asserter is not subject to criticism -she is actually subject to praise for having surmounted her previous beliefs - and offers an assertion which is both true and epistemically flawless, although she can be criticised for her beliefs, and because of these, she does not have knowledge. The upshot of these examples is that it is a mistake to require proper assertion to pass through the doxastic states of the asserter. Notice also that they are meant to be counterexamples both to $\mathrm{KN}$ and to $\mathrm{KB}$ (or one of its version such as KRB), hence to any account of assertion according to which the asserter has to occupy a certain epistemic status.

It is not clear, however, that such cases are genuine counterexamples to KAA and to $\mathrm{KN}$ in particular. In the first place it is not clear that although the subjects have religious or racist beliefs which run counter their assertions, they do not make these assertions on the basis of their evidence and of their knowledge (of evolutionary theory, of the innocence of the black man). In the second place, it is not clear that these cases are not cases where someone accepts that $\mathrm{P}$ although he or she does not believe that P. One can accept, for pragmatic or for non epistemic reasons of some kind (profession, role), and hence assert that $\mathrm{P}$, without believing that $\mathrm{P}$. At this point both the defender of KAA and its critic can have an answer ${ }^{4}$. On the one hand, the defender of KAA will want to say that to assert that $\mathrm{P}$ on the basis of an act of acceptance is merely to simulate assertion, or giving a fake assertion (not necessarily lying). On the other hand, the critic of the KAA will insist that these cases count as genuine assertions, although the subject is not in the appropriate epistemic status required by KAA or KB (or one of its versions). We meet again here the ambiguity already noticed above, between the claim that KAA states a norm for the correctness of assertions and the claim that it defines what an assertion is. The critic of KAA can claim that the case of selfless assertions, although they do not conform to the norm of correctness of assertion, count as assertions nevertheless.

\footnotetext{
${ }^{4}$ For the distinction between believing and accepting, see Cohen 192, Engel 2000. Jennifer Lackey considers the case of professional assertions, of lies and other cases, but considers that they are clear violations of the norm knowledge of assertion.
} 
At this point is becomes important to turn to the issue which is implicit from the beginning: in what sense is assertion subject to a norm?

\section{Which norm do we follow in assertion?}

The objections above show that there is a strong disagreement on this point. Two problems have to be distinguished. The first one is whether knowledge (or for that matter some sort of high epistemic status) is the only norm of assertion. In other terms, are our reasons for asserting a given sentence only epistemic and are the reasons for our being criticized in our assertions? One of the main reasons adduced in favour of the idea that knowledge is the norm of assertion by its defenders is that assertions which are not made in presence of proper knowledge can be "criticised". But are our reasons to criticize an assertion only epistemic reasons? The second problem is the problem of the relationship between the norm and its application.

Timothy Williamson addresses the first problem by replying to the kind of counterexamples mentioned in the previous section involving cases of assertion made in the absence of knowledge or belief in the asserted sentence, such as lying, speaking non seriously or making "selfless"assertions:

"Such cases do not show that the knowledge rule is not the rule of assertion. They merely show that it can be overridden by other norms not specific to assertion. The other norms do not give me warrant to assert $p$, for to have such warrant is to satisfy the rule of assertion" (Williamson 2000: 256)

The problem is whether an assertion can remain an assertion when it is uttered in the absence, or in the relative unimportance, of the epistemic status of the sentence uttered. Indeed the person who says "That's you train" intends to say this because there is an obvious cost in not asserting it, and because it is better in such cases to err on the side of prudence. There is no doubt that we make assertions for reasons which can be practical. In many of these cases we make, as I noticed above, acts of pragmatic acceptance without belief or without knowledge. It is clear that there can be assertions made for such pragmatic reasons, just as there can be can be (pragmatic) reasons for wanting to believe distinct from ( epistemic) reasons for belief. There is a clear sense in which a belief which is held for reasons which fall short of being epistemic - for instance a self deceptive belief or one which we aim to have to secure a form of comfort- still counts as 
a belief, so why could not assertions which are made for reasons which fall short of being epistemic, or which happen to be epistemically weak fail to count as assertions?

Commenting upon the example of "That's your train" and of assertions out of Gettierised beliefs, Jennifer Lackey says:

"There is a clear sense in which speakers who assert reasonably believed falsehoods and Gettierized beliefs are not subject to criticism. For the faultiness of the assertions in such cases result from infelicitous circumstances, not from any sort of blameworthy behaviour on the part of the asserters."( Lackey 2007: 597)

But the issue is precisely this: what kind of blameworthiness is at stake here? In the case of selfless assertions, the speakers are not blameworthy because they make assertions which are, although epistemically defective, perfectly proper. In the same manner, the liar, the joker, the ironist or the man who wants to reassure you by saying "That's no big deal" can be praised or blamed for their assertions for reasons why are distinct from their being epistemically valuable or not valuable. There is no doubt that they make assertions. This is not the point at issue, and we can here remove the first ambiguity noticed in $\S 1$ above: the KAA does not say that it is a defining feature of assertion (a necessary and sufficient condition) that it is governed by the norm of knowledge. It is perfectly compatible with KAA that some assertions violate the norm, and that other norms or dimensions of evaluation of assertions come into play. But from the fact that such norms can come into play in a number of assertions it does not follow that the other norm, the $\mathrm{KN}$ (or for that matter the KB or KRB norms) ceases to operate. Compare again with the contrast between reasons to believe and reasons for wanting to believe: the two can coexist or can conflict within a subject (for instance in selfdeception as it usually characterised), but the fact that it can be in some cases rational in a pragmatic sense to hold a belief for which one has only very weak epistemic reasons or evidence does not show that the main standard of evaluation of a belief is not truth or evidence. Similarly the fact that one can praise or blame an assertion in some cases for pragmatic reasons does not mean that the dimension of evaluation remains its epistemic status.

One might object that this answer relies too much on a parallel between belief and assertion, and that it is not a norm of assertion that it aims at truth or at knowledge 
contrary to the parallel claim about belief. ${ }^{5}$ Indeed it seems that in the case of assertion, we are entitled to adopt whichever norm we intend to adopt, depending on our specific aims, hence that the norms here are hypothetical imperatives. In the case of belief, they may be categorical. But is it the case? Certainly the liar, the ironist or the friendly asserter do make assertions, and they make them in the absence of knowledge (and of belief) of what they assert. But does it means that the point of their assertions was not truth or knowledge? If the objective of asserting that $\mathrm{P}$ were not to aim at one's audience recognising the truth of $\mathrm{P}$ (or believing or knowing that $\mathrm{P}$ - the kind of epistemic norm is not here in question - ) assertions would be pointless, even for the liar. Certainly the ties between belief and truth or knowledge are stronger than those between assertion and truth or knowledge, but it does not imply that they stop to operate in the case of assertion. The $\mathrm{KN}$ norm on assertion seems sometimes to be the view that our assertions should be so serious that only a Victorian clergyman - or an overly scrupulous scientist - could actually make assertions. But even the joker and the ironist have to recognise, if only implicitly the norm of truth and knowledge on assertion.

\section{4.. What it takes to obey the norm of assertion}

But it is precisely at this point - and it our second problem with the very idea of a norm of assertion - that we may ask: is not the norm KN too strong? Who will be ever able to obey it? Isn't it actually so strong that no one will ever be able to apply it? This was in part what was involved in the lottery case: there are actually many propositions (perhaps most of our beliefs) upon which we can have only a very high degree of belief, and no certainty or knowledge: if it were required that we know them, we would be entitled to assert nothing, or most of our assertions would fail ${ }^{6}$. Hence the KN norm would be trivial. After all, ought is supposed to imply can. Bernard Williams says:

\footnotetext{
${ }^{5}$ See e.g. Boghossian 2003 p.39: "The linguistic version of the normativity thesis, in contrast with its mentalistic version, has no plausibility whatsoever; and the reason for this is that it is not a norm of assertion that we should aim at the truth, in the way in which it is a norm of belief to do so." I have defend the normativity claim for belief in Engel 2005

${ }^{6}$ It is interesting here to note that this kind of objection has also been raised against normative account of belief in terms of truth: it is said that the norm for belief cannot be truth, since many truth cannot be believed and many truth are too trivial to be believable (see Boghossian op cit, Engel 2005). But since the norm of belief for assertion is arguably weaker than the knowledge norm $\mathrm{KN}$, the charge of being too strong would apply even for the weaker norm $(\mathrm{KB})$
} 
It has been claimed that the norm attached to assertion is knowledge, in the sense that in asserting that $p$ one represents oneself as knowing that $p$. The force of the claim might be thought to lie in the idea that one can be criticized for asserting what one does not know ("you should not have said this if you did not know"). This represents the criticism as a criticism of an assertor, but the speaker, after all, may not be in position himself to apply the norm effectively, because, at the point of asserting that $p$, he may reasonably think that he knows that $p$ when he does not. In such a case, it is not reasonable to criticize him, in the sense, at least of blaming him for not having remained silent rather than speaking, or for not having said that $\mathrm{p}$ only in some qualified or doubtful way. It may be said, as it can in the case of many other rules, that he has broken the norm, but that in these circumstances he is not to blame for doing so. But then we still need to know the supposed norm applies, and what the consequences of its obtaining are supposed to be." (Williams 2002: 76-77)

Here some defenders of the KAA account often use a distinction put forward by Keith DeRose between the primary and the secondary propriety or impropriety of a norm:

"As it happens with other rules, a kind of secondary propriety / impropriety will arise with respect to KN. While those who assert appropriately (with respect to this rule) in a primary sense will be those who actually obey it, a speaker who broke this rule in a blameless fashion ( one who asserted something she didn't know, but reasonably thought she did know, would in some secondary sense be asserting properly." (De Rose 2002: 180)

In other words, one could violate a norm of assertion in the primary sense, while not violate it in the secondary sense, hence not being open to criticism in the primary sense; alternatively one can violate the norm in the secondary sense and not be criticisable in the primary sense. Some writers, like Matt Weiner (2005), use this distinction to defend the norm of truth (KT) for assertion against the $\mathrm{KN}$ norm: the speaker may not be able to respect the stronger norm $(\mathrm{KN})$, but he has to respect in any case the weaker one to make a proper assertion: the only case where one is liable to criticism, on the view in question, is the case where the asserter has no grounds for believing the uttered sentence to be true (as in the paradoxical sounding (7') above). Now I agree with Lackey (2007: 603-607) that this distinction is spurious, because there is only one way of violating a norm: simply by not doing or believing what it prescribes. The fact that I am unaware that I crossed the yellow line does not make me less liable to receive the fine from the policeman who notices my bad driving behaviour. That may excuse me, but that does not change the fact that I have violated the rule. The fact that one is unaware of violating the norm does not change one's status with respect ot the norm. 
Williams' objection and DeRose's distinction, however, although they do no signal different ways of respecting or violating a norm, point to another distinction which it is important to make, between the statement of a norm and its regulation. On the one hand a norm can be formulated in an objective sense, as a correctness condition of the form

Practice $\mathrm{P}$ is correct only if it has feature $\mathrm{C}$

or as an imperative

One must: perform practice $\mathrm{P}$ only if one satisfies feature $\mathrm{C}$

$\mathrm{KT}, \mathrm{KB}$ and its variants, as well as $\mathrm{KN}$ as formulated above are formulated in terms of such correctness and imperative conditions.

But on the other hand there are the conditions under which a norm is regulated, or its regulation conditions. These are the subjective conditions under which the correctness conditions are accessed by a given individual and are implemented in his psychology. ${ }^{7}$ The former are independent of what the subject believes to be the norm, whereas the latter are so dependent. Of course the two do not have to be completely independent, for otherwise one could not see how the norm is regulated, but they need not necessarily coincide.

In the case of the knowledge norm for assertion, the relevant distinction is between (i) the question whether a subject's assertion are conform to the norm, and (ii) whether the subject actually believes that his or her assertion are conform to the norm. Many criticism of the KN rule actually assume that conformity to the norm implies (ii). This is why, as we saw above in $\S 1$, a number of formulations consider that the norm $\mathrm{KN}$ has to include the correctness conditions that the subject "represents himself" as knowing the content of the assertion, or some other kind of "self-presentation". As we saw, the self presentation account in the form (1) above, is clearly inadequate. But the KNB form, which Williamson (2000: 260) formulates as:

(the $\mathrm{BK}$ rule) : One must: assert $\mathrm{P}$ only if one believes that one knows $\mathrm{P}$

Is not obviously so inadequate. As Williamson notes, saying that the asserter has only to believe that he knows, or take himself to know, can explain many conservational phenomena which the $\mathrm{KN}$ account explain, without asking a correctness condition as strong as knowing the

\footnotetext{
7 Although there are many ways of doing this distinction, I was inspired by the way in which Shah (2003) formulates a similar distinction with respect to the norm of truth for belief. See Engel (2008).
} 
content of the assertion. But Williamson rightly objects to it that even if we add to BK the condition that the belief has to be rational (for one might irrationally believe that one knows), one can rationally believe oneself to know that $\mathrm{P}$ while not knowing that $\mathrm{P}$, hence violating the norm KN (Williamson 2000: 262). I agree with him that the right move, for the defender of KN is not to relativise it to a belief or to some mental attitude whereby the subject represents to himself the norm.

It is certainly difficult to say that an agent does not need in any sense to have access to a norm in order to follow it, and familiar attempts to reduce rules and norms to dispositions or rules to tacit knowledge of rules fail in this respect. But it is not clear that one needs to actually believe anything about the norm in order to apply it and to perform assertion. Someone who asserts a sentence in the future tense - "there will be sea fight"- obviously does not know, and does not believe that he knows, the existence of the future state of affairs described by the sentence. Nevertheless he makes an assertion, and he conforms himself to the KN norm. A liar obviously does not believe what he asserts, hence he does not know it. He nevertheless makes an assertion. It does not matter here whether we say that the $\mathrm{KN}$ norm is a conventional feature of assertion in a language in general, or whether it is a commitment of individual speakers. The point is that the norm is presupposed even when other norms, such as truthfulness, social norms, or other determinants of what we may want to say, are in place. The fact that the norm can be in many cases violated, overridden by other norms, or be applied in a very loose and relaxed way in many conversational circumstances does not show that the norm is not in place. ${ }^{8}$ Similarly the fact that it is most often (in most of the cases) very hard to implement does not show that it is not in place. We certainly sometimes do not have the slightest idea of what it would take for us to know the things that we assert. But is does not imply that we do not have any idea of what it would take to know anything. In so far as the standard of knowledge is with us in quite many cases (I would argue for many so called "Moorean" propositions, such as that there are trees in the garden across my window), it is enough for us to have it for most assertions. It is not because we cannot attain certain kinds of knowledge that the norm is not in place. In this sense, ought does not necessarily imply can.

\section{Conclusion}

\footnotetext{
${ }^{8}$ I here concur completely with Williamson $2000: 258-59$
} 
I have not, in this paper, tried to examine all the objections that have or can be raised against the KAA. Neither I have dealt with the issue whether another epistemic norm than knowledge ( warrant or rational credibility) should not be preferred to KN. In fact most of the arguments that I have presented are compatible with the view that some high epistemic status, be it knowledge or not, is a norm of assertion, although there are some good reasons, which I have not given here, to prefer the knowledge account. My main point has consisted in objecting that the knowledge norm is confused or inapplicable does not threaten the claims of KAA, once we understand what it takes to be a norm of assertion. ${ }^{9}$

\footnotetext{
${ }^{9}$ versions of this paper have been read in 2007 in York, Nottingham, Geneva and Nancy. For their comments and encouragements I thank Tom Baldwin, Steven Barker, Berit Brogard, Greg Currie, Igor Douven Julien Dutant, Frank Lihoreau, Kevin Mulligan, Paul Noordhof, Ortto Bruun, Tom Stoneham. I am also indebted to the participants of a workshop that I organised at the University of Paris IV in january 2006, Manuel Garcia Carpintero, David Owens, Maria van der Schaard, and Peter Pagin, whose 2006 article inspired me much.
} 


\section{References}

Boghossian, P. 2003 “the Normativity of content”, Philosophical Issues, 13, 2003, pp. 32-45

Cohen, J. 1992 An Essay on Belief and Acceptance, Oxford, Oxford University Press

Davidson, D. 1979 "Communication and Convention", in Inquiries into Meaning and interpretation, 1984 Oxford: Oxford University Press

De Rose, K. 2002 “Assertion, Knowledge and Context”, Philosophical Review, 111, 2, 167-203

Douven, I. 2006 “Assertion, Knowledge and Rational credibility” Philosophical Review, 115: 449-485

Dummett, M. 1973 Frege, Philosophy of language, London: Duckworth

Engel, P. 2000 ed. Believing and accepting, Kluwer, Dordrecht

2005 "Truth and the Aim of Belief", in D. Gillies, ed. Laws and

Models in science, London: King's college Publications

2008 "Belief and Normativity", Disputatio, 23, 153-177

Frede, M 1987 “The Skeptic's two kind of assent” Frede, in Essays in Ancient

Philosophy, Minneapolis: University of Minnesota Press

Hawthorne, J. 2004 Knowledge and Lotteries, Oxford, Oxford University Press

Lackey, J 2007 "Norms of Assertion." Noûs 41 (2007): 594-626.

Marcus, R. B 1983 "Rationality and Believing the impossible", Journal of

Philosophy, LXXX, 6, 321-338, repr. in her Modalities, Oxford,

Oxford University Press, 1993, pp. 143-161

Mates, B. The skeptics's way, tr. Of Sextus Empiricus, Outlines of Pyrrhonism, Berkeley, University of California Press

Moore, G.E. 1962, Common place book, ed. C. Lewy, Cambridge, Cambridge University Press

Pagin, P. 2004 "Is assertion social?", Journal of Pragmatics , 36, 833-859.

2006 "Knowledge account of assertion", talk at the workshop "Assertion and knowledge", University Paris IV, january 2006, new version 2007 at http://people.su.se/\%7Eppagin/papers/astnorm.pdf

Shah, N. 2003 "How truth Governs Belief", Philosophical Review, 112: 447-82

Unger, P. 1975 Ignorance, Oxford, Oxford University Press

Weiner, M. 2005 “Must we Know what we Say ?" Philosophical Review, 114, 227-251

Williams, B. 2002 Truth and truthfulness, Princeton, Princeton University

Press

Williamson T. 2000 Knowledge and its Limits, Oxford: Oxford University Press 